\title{
TECHNICAL AND SCALE EFFICIENCIES OF U.S. GRASS-FED BEEF PRODUCTION: WHOLE-FARM AND ENTERPRISE ANALYSES
}

\author{
BERDIKUL QUSHIM* \\ Gulf Coast Research and Education Center, University of Florida, Wimauma, Florida \\ JEFFREY M. GILLESPIE \\ U.S. Department of Agriculture, Economic Research Service, Market and Trade Economics Division, Washington, DC \\ BASU DEB BHANDARI \\ Comerica Bank, Dallas, Texas; and Louisiana State University, Department of Agricultural Economics, Baton Rouge, \\ Louisiana
}

GUILLERMO SCAGLIA

Louisiana State University AgCenter, Iberia Research Station, Jeanerette, Florida

\begin{abstract}
A stochastic production frontier approach was used to estimate input distance functions for U.S. grass-fed beef (GFB) production. Average technical efficiencies of 0.84 and 0.79 were found for U.S. GFB whole farms and enterprises, respectively. Producer education level, experience, farm size, annual net farm income from the GFB operation, annual net household income from off-farm sources, and regional differences are the efficiency drivers of U.S. GFB farms. Increasing returns to scale were found for U.S. GFB farms. Our results suggest that U.S. GFB farms can be scale efficient if the optimal size of the operation is greater than approximately $100 \mathrm{GFB}$ animals.
\end{abstract}

Keywords. Grass-fed beef, input distance function, returns to scale, scale and scope economics, stochastic production frontier, technical efficiency

JEL Classifications. Q10, Q12

\section{Introduction}

Grass-fed beef (GFB) production in the United States has experienced growth and increased research and development attention over the last two decades because of human health, environmental, animal welfare, and sustainability perspectives (Mills, 2003; McCluskey et al., 2005). According to Williams

The authors acknowledge funding from the National Institute of Food and Agriculture, Agriculture and Food Research Initiative (2011-67023-30098) and U.S. Department of Agriculture Hatch funds (LAB94178). Any opinions, findings, conclusions, or recommendations expressed in this publication are those of the author(s) and do not necessarily reflect the views of the USDA.

*Corresponding author’s e-mail: berdikul@gmail.com 
(2013), domestically produced GFB retail sales increased from less than $\$ 5$ million with only about 100 GFB producers in 1998 to $\$ 400$ million in 2012. Consumer survey results have shown that $20 \%-30 \%$ of U.S. beef consumers are willing to pay premium prices for GFB (Cox et al., 2006; Umberger et al., 2002). Furthermore, the U.S. imports GFB from New Zealand and Australia (Umberger, Boxall, and Lacy, 2009; U.S. Department Agriculture, Economic Research Service [USDA-ERS], 2015), suggesting the U.S. GFB industry has significant growth potential. Existing and potential GFB producers can benefit from knowing how their operations can be structured to become more efficient and profitable. The present study evaluates productivity and profitability measures of GFB production and the variables that influence the production efficiency of U.S. GFB operations. We are unaware of previous studies that have focused on the efficiency of GFB operations.

Though demand for GFB appears to be increasing, GFB production continues to represent a small percentage of U.S. beef production. Gwin (2009) estimated GFB production at 50,000-100,000 head in 2008 , constituting less than $0.5 \%$ of the total U.S. beef produced. This is supported by Pelletier, Pirog, and Rasmussen (2010), who reported the share of GFB production to be less than $1 \%$ of total U.S. beef produced. Nonetheless, it has become easier for U.S. consumers to identify sources of GFB for purchase, as casual observation suggests it is now available in more grocery stores, restaurants, and farmers' markets than 10 years ago. Supporting these casual observations, Mathews and Johnson (2013) state that alternative beef production, which includes organic, natural, and grass-fed, constitutes about $3 \%$ of the total U.S. beef market and has grown about $20 \%$ per year in recent years. The GFB segment is part of a larger U.S. beef industry that is the second-largest U.S. agricultural industry. The U.S. beef industry is the largest fed cattle industry in the world and the world's largest producer of beef (USDA-ERS, 2012).

Though limited research has addressed GFB farm efficiency, several studies have examined beef cow-calf industry production performance measures. Studies have estimated the technical, allocative, and scale efficiencies of cow-calf farms using a nonparametric linear programming-based approach known as data envelopment analysis (Featherstone, Langemeier, and Ismet, 1997; Rakipova, Gillespie, and Franke, 2003). Farm size significantly affected technical efficiency (TE); herd sizes of farms up to 48 beef cows exhibited substantial economies of scale (Featherstone, Langemeier, and Ismet, 1997). European beef cattle farm TE and profitability have been examined using a stochastic production frontier (SPF) model, focusing on the possible impacts of the Common Agricultural Policy (Iraizoz, Bardaji, and Rapun, 2005). Samarajeewa et al. (2012) determined the relative efficiency measures of cowcalf farms in Alberta, Canada. We are, however, unaware of any technical or economic efficiency studies that have analyzed GFB production in the United States. 
The overall objective of this study is to determine the economic factors influencing the productivity of U.S. GFB production. The specific objectives are to determine: (1) the effects of farm specialization, farm size, and farmer demographics on the TE of U.S. GFB production; (2) the marginal productive contributions (MPCs) of inputs and outputs in U.S. GFB production; and (3) the extent of economies of scale and scope economies in U.S. GFB production. Each of these productivity measures is estimated on both whole-farm and GFB enterprise bases. Costs of production for different sizes of GFB operations are estimated, and results are compared. We estimate a stochastic input distance function (IDF) using SPF techniques.

\section{Model and Methods}

To estimate efficiency, a multidimensional (input and output) production technology is required. A general form for such a technology may be characterized by a stochastic IDF. The stochastic IDF approach allows us to evaluate U.S. GFB farm production technology and efficiency. In the absence of price information for inputs and outputs or when cost, profit, or revenue function estimation is impossible because of violations of required behavioral assumptions, the stochastic IDF is an appropriate method allowing for the specification of a multiple-output/multiple-input technology (Coelli and Perelman, 1999). The stochastic IDF and the cost frontier are dual functions, and TE can be estimated econometrically from the stochastic IDF (Kumbhakar and Lovell, 2000).

A reason to choose the IDF approach rather than an output distance function to represent GFB farms' technological structure is farmers' greater short-term control over their input than output decisions. There are a number of potential advantages of the translog IDF: (1) efficient econometric estimates of the parameters can be obtained, (2) one can formally test the hypothesis of systematic deviations from the production technology frontier, (3) the issue of potentially endogenous regressors in the distance function can be addressed using the firstorder equations, (4) scope economies can be determined from the estimates, and (5) firm-specific technical inefficiency measures as a by-product of estimation can be obtained (Coelli, Hajargasht, and Knox Lovell, 2008). The reader is referred to Coelli, Hajargasht, and Knox Lovell (2008) for greater detail on this function.

A stochastic IDF is defined as the set of inputs $L(Q, R)$ that can produce a given output vector $Q$ with minimum input set $X$ (Coelli et al., 2005):

$$
D^{I}(X, Q, R)=\max \left\{\lambda: \frac{X}{\lambda} \in L(Q, R)\right\}, X \in \mathcal{R}_{+}^{m}, Q \in \mathcal{R}_{+}^{k} \text {, and } R \in \mathcal{R}_{+}^{s} \text {, }
$$


where $X$ is defined as the input set in the Euclidean $m$-space $\mathcal{R}_{+}^{m} ; Q$ is defined as output set in the Euclidean $k$-space $\mathcal{R}_{+}^{k}$; and $R$ is defined as the farm efficiency determinants set in the Euclidean $s$-space $\mathcal{R}_{+}^{S}$.

The stochastic IDF can be estimated econometrically using SPF techniques, which requires imposing homogeneity of degree one on the inputs for $D^{I}(X, Q, R)$. The value of the distance will be $D^{I}(X, Q, R) \geq 1$. An IDF is nondecreasing, concave, and linearly homogeneous in inputs, and nonincreasing and quasi concave in outputs. This homogeneity condition implies that $D^{I}(\delta X, Q, R)=\delta D^{I}(X, Q, R)$ for any $\delta>0$, and $\delta$ can be set arbitrarily at $1 / X_{m}$, resulting in $D^{I}(X, Q, R) / X_{m}=D^{I}\left(X / X_{m}, Q, R\right)=D^{1}\left(X^{*}, Q, R\right)$, where $X^{*}$ is a vector of inputs normalized by $X_{m}$.

To limit a priori restrictions on the relationships among inputs and outputs, the stochastic IDF may be approximated using a translog functional form for empirical implementation. To reveal the production technology, a translog functional form for the stochastic IDF is specified as

$$
\begin{aligned}
\ln D_{i}^{I}(X, Q, R)= & \alpha_{0}+\sum_{m} \alpha_{m} \ln X_{m i}+\frac{1}{2} \sum_{m} \sum_{n} \alpha_{m n} \ln X_{m i} \ln X_{n i} \\
& +\sum_{k} \beta_{k} \ln Q_{k i}+\frac{1}{2} \sum_{k} \sum_{l} \beta_{k l} \ln Q_{k i} \ln Q_{l i} \\
& +\sum_{k} \sum_{m} \theta_{k m} \ln Q_{k i t} \ln X_{m i}+\sum_{s} \varphi_{s} R_{s i}+\vartheta_{i} .
\end{aligned}
$$

Homogeneity of degree 1 in inputs implies the parametric restrictions $\sum_{m} \alpha_{m}=1, \sum_{n} \alpha_{m n}=0$, and $\sum_{k} \theta_{k m}=0$. By Young's theorem, the symmetry restrictions are $\alpha_{m n}=\alpha_{n m}$ and $\beta_{k l}=\beta_{l k} \forall m, n, k, l$.

To impose the homogeneity restrictions in the present study, we divided all inputs and the distance term $D_{i}^{I}(X, Q, R)$ by a numeraire input, land, specified as $X_{m}=X_{L A N D}$, which is consistent with much of the literature on land-based farm production. The function is specified on a per dollar of land basis as

$$
\begin{aligned}
\ln \frac{D_{i}^{I}(X, Q, R)}{X_{1, i}}= & \alpha_{0}+\sum_{m} \alpha_{m} \ln X_{m i}^{*}+\frac{1}{2} \sum_{m} \sum_{n} \alpha_{m n} \ln X_{m i}^{*} \ln X_{n i}^{*} \\
& +\sum_{k} \beta_{k} \ln Q_{k i}+\frac{1}{2} \sum_{k} \sum_{l} \beta_{k l} \ln Q_{k i} \ln Q_{l i} \\
& +\sum_{k} \sum_{m} \theta_{k m} \ln Q_{k i} \ln X_{m i}^{*}+\sum_{s} \varphi_{s} R_{s i}+\vartheta_{i}
\end{aligned}
$$

which can be rewritten in general form as

$$
\begin{gathered}
-\ln X_{1, i}=T L\left(X^{*}, Q, R\right)+\vartheta_{i}-\ln D_{i}^{I}(X, Q, R) \\
=T L\left(X^{*}, Q, R\right)+v_{i}-u_{i},
\end{gathered}
$$

where $i=85$ is the number of farms; $k, l$, the outputs; and $m, n$, the inputs. $X_{1}$ is land, specified as a normalization factor in inputs. The input variables 
$\left(X^{*}\right)$ with asterisk symbols indicate ratios of all input variable values to the quality adjusted land price. Equation 4 contains two outputs and two inputs for both whole-farm and GFB enterprise analyses. Regional dummy variables $(R)$ are also included in this equation. The distance $\ln D_{i}^{I}(X, Q, R)$ from the frontier characterizes the technical inefficiency error, $-u_{i}$. This random one-sided error, $u_{i} \geq 0$, is independently distributed with truncation at zero of the $N\left(\mu_{i}, \sigma_{u}^{2}\right)$ distribution, where $\mu_{i}=\sum_{f} \mathrm{~W}_{f} \delta, \mu_{i}$ is defined as the conditional mean of $u_{i}, \mathrm{~W}_{f}$ is a vector of farm efficiency determinants, and $\delta$ represents unknown estimable parameters. Specifically, technical inefficiency is a function of farm- and farmerspecific characteristics. TE is derived as the expectation of $-u_{i}$ conditional on error term $\varepsilon_{i}=v_{i}-u_{i}$ (Jondrow et al., 1982) and is measured as $T E=\exp ^{-u_{i}}$.

Rational producers should care about economic performance measures such as MPCs of inputs and outputs in optimizing input use, returns to scale (RTS) or scale economies, and scale efficiency (SEF) in producing at the optimal farm size, and scope economies in reducing average cost by producing multiple outputs if applicable. The productivity impacts or MPCs of outputs or inputs can be estimated from the stochastic IDF model by the first-order elasticities. Using the first-order elasticities from the stochastic IDF, output and input MPCs can be estimated, respectively, as

$$
\begin{gathered}
M P C_{k}=-\varepsilon_{D^{I} Q_{k}}=-\partial \ln D^{I}(X, Q, R) / \partial \ln Q_{k}=\varepsilon_{X_{1} Q_{k}} \text { and } \\
M P C_{m}=-\varepsilon_{D^{I} X_{m}^{*}}=-\partial \ln D^{I}(X, Q, R) / \partial \ln X_{m}^{*}=\varepsilon_{X_{1} X_{m}^{*}}
\end{gathered}
$$

$M P C_{k}$ indicates the increase in overall input use when output expands (and so is expected to be positive, like a marginal cost or output elasticity measure), and $M P C_{m}$ indicates the shadow value (Färe and Primont, 1995) of the $m$ th input relative to $X_{1}$ (and so is expected to be negative, like the slope of an isoquant).

Scale economies or RTS are calculated as the combined contribution of the $K$ outputs $Q_{k}$, or the scale elasticity (SE):

$$
S E=-\varepsilon_{D^{I} Q_{k}}=-\sum_{k} \partial \ln D^{I}(X, Q, R) / \partial \ln Q_{k}=\varepsilon_{X_{1}, Q}
$$

That is, the sum of the input elasticities, $\sum_{k} \partial \ln X_{1} / \partial \ln Q_{k}$, indicates the overall input-output relationship and thus RTS. The extent of scale economies is thus implied by the shortfall of scale economies from 1 ; if scale economies $<1$, inputs do not increase proportionately with output levels, implying increasing RTS. A measure of scope economies was estimated from the stochastic IDF by taking the second cross partial output derivatives, $\partial^{2} \ln D^{I}(X, Q, R) / \partial \ln Q_{k} \partial \ln Q_{l}>0$. The scope economy measure ranges between 0 and 1 , indicating no scope economy if it is equal to 0 .

SEF is the potential productivity gain from moving to the optimal farm size and can be estimated from the stochastic IDF. The method for estimating SEF was introduced by Ray $(1998,2003)$ and Balk (2001) for single-output multiple-input 
and multiple-output multiple-input distance functions. Following Ray (2003), the SEF for U.S. GFB production can be estimated from the stochastic IDF as

$$
\operatorname{SEF}(X, Q, R) \exp \left(\left\{-\left[1-\sum_{k} \partial \ln D^{I}(X, Q, R) / \partial \ln Q_{k}\right]\right\}^{2} / 2 \sum_{k} \sum_{l} \beta_{k l}\right)
$$

The SEF measure ranges between 0 and 1, indicating SEF exists if the SEF measure is equal to 1 .

We used Stata's nonlinear combinations of estimators (or nlcom) command to estimate the statistical significance of MPCs for inputs and outputs, scale economies, RTS, elasticities, and SEF measures for the GFB production because the stochastic IDF is not a linear function. This estimation is based on the delta method.

\subsection{Data}

During August-September 2013, a mail survey of 1,050 U.S. GFB producers was conducted to determine their use of production and marketing practices, farm operation characteristics, management practices, criteria for selecting animals for grass finishing, pasture and grazing management for the GFB operation, producer goals and reasons for selecting the GFB enterprise, perceptions of challenges facing the GFB industry, preferences for breeding stock, general financial information, and producer demographics. The mailing list of U.S. GFB producers was created by searching the Internet for addresses of GFB producers, specifically visiting the American Grass-Fed Association (www.americangrassfed.org/) and MarketMaker (https://foodmarketmaker.com/) websites, Eatwild.com, and other sites that were identified where GFB producers advertised their products. All GFB producers for which a mailing address could be obtained were included. The questionnaire, a signed letter, and business-reply envelope were sent to producers on August 4, 2013, followed by a postcard reminder 1 week later. On August 28, 2013, a second questionnaire, signed letter, and business-reply envelope were sent to nonresponders, followed by a postcard reminder 1 week later. The Dillman, Smith, and Christian (2009) tailored design method was followed in preparing the survey. Of the 1,050 surveys sent throughout the United States, 384 responses were collected for an adjusted response rate of $41 \%$, considering bad addresses and producers no longer in the GFB business.

The last question in the survey asked GFB producers about their willingness to fill out a follow-up survey on cost and returns of GFB production in 2012. A total of 257 GFB producers agreed to complete the follow-up survey questionnaire. The follow-up questionnaire was designed in a similar manner to USDA's Agriculture Resource Management Survey questions on costs and returns. Detailed information on income and expenses was collected using this survey. Because respondents had already received up to four mailings on the first survey, we sent only two mailings of the follow-up questionnaire 2 weeks apart, both with personally addressed, signed letters and business-reply envelopes. For 
Table 1. Summary Statistics and Variable Definitions for U.S. Grass-Fed Beef (GFB) Producers

\begin{tabular}{|c|c|c|c|}
\hline Variable & Definition & Mean & $\begin{array}{l}\text { Standard } \\
\text { Deviation }\end{array}$ \\
\hline Cropl & All crops and other livestock production, $\$$ & $54,640.28$ & $148,044.60$ \\
\hline Gfed & $\begin{array}{l}\text { GFB animal and meat production including } \\
\text { hay sold from pasture devoted to GFB } \\
\text { production, } \$\end{array}$ & $57,436.72$ & $103,003.00$ \\
\hline$G f b a h$ & $\begin{array}{l}\text { GFB animal production including hay sold } \\
\text { from pasture devoted to GFB production, } \\
\$\end{array}$ & $12,840.28$ & $23,356.26$ \\
\hline Gfbm & GFB meat production, $\$$ & $44,596.99$ & $103,514.90$ \\
\hline Landw & $\begin{array}{l}\text { Quality-adjusted land value, service flow } \\
\text { (whole farm), \$ }\end{array}$ & $80,987.99$ & $194,783.60$ \\
\hline Lande & $\begin{array}{l}\text { Quality-adjusted land value, service flow } \\
\text { (enterprise), \$ }\end{array}$ & $58,100.46$ & $155,565.10$ \\
\hline Varw & Total other variable expenses (whole farm), \$ & $59,103.81$ & $73,305.07$ \\
\hline Vare & Total other variable expenses (enterprise), \$ & $35,681.92$ & $46,239.56$ \\
\hline Fixw & Total fixed expenses (whole farm), \$ & $49,091.27$ & $85,813.55$ \\
\hline Fixe & Total fixed expenses (enterprise), \$ & $28,468.66$ & $38,589.57$ \\
\hline College & $\begin{array}{l}\text { Dummy variable for producer holding } \\
\text { 4-year college or higher degree }\end{array}$ & 0.69 & 0.46 \\
\hline $\operatorname{Exp}$ & Years producing GFB & 11.30 & 7.95 \\
\hline Farmsize & $\begin{array}{l}\text { Continuous variable for total number of } \\
\text { GFB animals in inventory }\end{array}$ & 94.2 & 122.03 \\
\hline Gfbinc & $\begin{array}{l}\% \text { of annual net farm income from the GFB } \\
\text { enterprise: } 1, \leq 19 \% ; 2,20 \%-39 \% ; 3, \\
40 \%-59 \% ; 4,60 \%-79 \% ; 5,80 \%-100 \%\end{array}$ & 2.90 & 1.75 \\
\hline Offfarm & $\begin{array}{l}\% \text { of annual net household income from } \\
\text { off-farm sources: } 1, \leq 19 \% ; 2,20 \%-39 \% \text {; } \\
3,40 \%-59 \% ; 4,60 \%-79 \% ; 5 \\
80 \%-100 \%\end{array}$ & 3.39 & 1.65 \\
\hline Seast & $\begin{array}{l}1 \text { if in states AR, FL, GA, KY, LA, MD, MS, } \\
\text { MO, SC, VA, WV; } 0 \text { otherwise }\end{array}$ & 0.22 & 0.42 \\
\hline Neast & $\begin{array}{l}1 \text { if in states CT, MA, NH, NY, PA; } 0 \\
\text { otherwise }\end{array}$ & 0.22 & 0.42 \\
\hline Mwest & $\begin{array}{l}1 \text { if in states MI, MN, IL, IN, OH, WI; } 0 \\
\text { otherwise }\end{array}$ & 0.23 & 0.43 \\
\hline West & $\begin{array}{l}1 \text { if in states AZ, CA, CO, ID, MT, NE, OR, } \\
\text { SD, TX, UT, WA, WY; } 0 \text { otherwise }\end{array}$ & 0.33 & 0.47 \\
\hline
\end{tabular}

the follow-up survey questionnaire, a total of 85 completed responses were received from producers in 34 states (see Table 1, which lists the states by region). After adjusting for undeliverable surveys, producers who did not produce GFB, and incomplete surveys, the effective return rate was $33 \%$.

Using the costs and returns data (Table 1), we developed two outputs for both the GFB whole-farm and enterprise IDF analyses. For the whole-farm analysis, 
Gfed is the revenue from GFB meat and animal sales, plus revenue from hay sold from pasture devoted to GFB production. Cropl is revenue from all crops and other livestock (non-GFB) sales. For the enterprise analysis, $G f b a b$ is revenue from GFB animal production plus revenue from hay sold from pasture devoted to GFB production. $\mathrm{G} f b m$ is revenue from GFB meat sales. ${ }^{1}$ Inputs for both analyses include: Land is quality-adjusted land price; ${ }^{2}$ Var is total variable expenses; ${ }^{3}$ and Fix is total fixed expenses and hired labor expenses. ${ }^{4}$ Much of the previous research has used monetary values rather than quantities for output and input variables and aggregated all livestock outputs as one output (Morrison Paul and Nehring, 2005; Qushim et al., 2016). These studies have been national in scope. We followed these studies and used monetary values for our input and output variables.

In Table 1 , the letters " $e$ " or " $w$ " at the end of each input variable indicate the value for the GFB enterprise or for the whole farm, respectively. For most of the expenses, we requested that the respondent provide the total farm expense and an estimate of the expense that was allocated to the GFB enterprise. We did not, however, request enterprise-specific expenses for the following inputs in the survey questionnaire: Repairs on Equipment; Insurance; Taxes; Vehicle/Licensing Fees; Depreciation; Custom Work; Cash Value of Feed, Farm Commodities, Fuel, Housing, Meals, Other Food, Utilities, and Vehicle for Personal Use; and Farm Management Services. In order to obtain enterprise-specific expenses for these input variables for the enterprise analysis, the percentage or portion of the GFB enterprise total return was calculated as the total GFB enterprise return (GFBER) divided by the total whole farm return (WFR) to result in GFBER/WFR. For the GFB enterprise-specific expenses for these inputs, the whole-farm expense values were multiplied by GFBER/WFR. For the whole-farm analysis, total farm returns and expenses were used.

1 A limitation of the study is that it is possible that prices for GFB animals and meat may vary by region. We do not have evidence of this for 2012, as we know of no sources of regional prices for GFB meat or animals for that year. Recent USDA, Agricultural Marketing Service (2017) Grass Fed Beef Market Reports have shown prices for four GFB cuts over four regions for 2017, and there has been some regional variation by cut.

2 State-level quality-adjusted land values are used for the United States as estimated in Ball et al. (2008) to account for land heterogeneity.

3 Total variable expenses include feed expenses, marketing charges, seed and plant expenses, fertilizer and chemical expenses, purchased livestock expenses, bedding and litter expenses, medical supplies including veterinary and custom services, fuel and oil expenses, electricity expenses, all other utility expenses, farm supplies and marketing containers including hand tools, maintenance and repair including parts and accessories expenses, machine hire and custom work expenses, other livestock related expenses, and other variable expenses.

4 Total fixed expenses include depreciation, insurance, interest and fees paid on debts, property taxes, rental and lease payment expenses, and hired labor expenses. Hired labor expenses include cash wages paid to hired farm and ranch labor plus payroll taxes and benefits. It also includes cash wages, incentives and bonuses, and payment to other operators and paid family members if they received a wage. 
Missing information is a common issue for survey data and may result in biased estimates and reduce regression estimate efficiency (Rubin, 1987). Various methods exist to handle missing data issues. The multiple imputation method (Rubin, 1987; Schafer, 1997), specifically the truncated regression imputation method, was used to estimate missing values of continuous variables in this study. We imputed eight values for missing depreciation expenses and six values for missing cash value of noncash payment for farmwork expenses incorporating farm characteristics and demographics from the earlier GFB survey. Neast, Mwest, and West are regional dummy variables for the northeastern, midwestern, and western U.S. GFB production regions, respectively (Seast is the base southeastern GFB production region). States included in each region are shown in Table 1. We grouped U.S. states into the regions based on U.S. farm resource regions as designated by USDA-ERS and similarity of states in terms of forage type, land, and weather conditions.

Having zero-value observations in estimation of the translog function may prove problematic, resulting in biased estimators of parameters of the chosen function (Battese, 1997). A few observations in the Cropl and Gfbah variables may have zero values in our sample in cases where farms did not produce crops or sell animals, respectively. We caution readers that not all observations have zero values in these variables. Note that having a few zero-value observations may affect results of parameter estimates. Therefore, we used the Battese (1997) approach to deal with zero-value observations:

$$
\begin{aligned}
& \sum_{k=1} Q_{k, i}^{d}=1 \text { if } \sum_{k=1} Q_{k, i}=0, \sum_{k=1} Q_{k, i}^{d}=0 \text { if } \sum_{k=1} Q_{k, i}>0, \\
& \quad \text { and } \sum_{k=1} Q_{k, i}^{*}=\max \left(Q_{k, i}, Q_{k, i}^{d}\right),
\end{aligned}
$$

where $i$ denotes the number of observations, $k=1$ is $Q_{C r o p l}$ (for the whole-farm analysis) or $Q_{G f b a b}$ (for the enterprise analysis), and $Q_{k, i}^{d}$ is a dummy variable accounting for the intercept change.

We also include farm-specific TE variables (W) from the GFB production survey data. The following GFB production technical inefficiency effects model was estimated as a function of farm and producer characteristics for both wholefarm and enterprise analyses:

$$
\mu_{i}=\tau_{0}+\tau_{1} R_{\text {College }}+\tau_{2} R_{\text {Exp }}+\tau_{3} R_{\text {Farmsize }}+\tau_{4} R_{\text {Gfbinc }}+\tau_{5} R_{\text {Offfarm }}+\epsilon_{i}
$$

where $\mu_{i}$ is defined as the conditional mean of $u_{i}, \epsilon_{i}$ is unobservable independently distributed random variables, and the farm-specific $\mathrm{W}_{f}$ variables are defined in Table 1.

College is a producer education dummy variable indicating whether the respondent held a bachelor's degree or higher. Producers with higher educational attainment have generally been more technically efficient (Morrison Paul et al., 2004; Rakipova, Gillespie, and Franke, 2003). Exp is a continuous variable 
indicating the number of years the producer had raised GFB. Producers with more farming experience are likely to have more knowledge of farming practices; experience has generally positively affected TE (Bhatt and Bhat, 2014).

Farmsize is continuous variable for operation size in terms of animals in inventory. Farms have generally been more technically efficient with increasing size (Featherstone, Langemeier, and Ismet, 1997; Morrison Paul et al., 2004; Samarajeewa et al., 2012). Gfbinc is the percentage of annual net farm income from the GFB enterprise, categorized into five levels in $20 \%$ intervals, a measure of farm specialization. A positive impact of degree of specialization on TE would be expected if specialization improves the producer's ability to manage the operation. Previous studies have shown mixed results on the impact of specialization on TE of livestock farms. Featherstone, Langemeier, and Ismet (1997) found that specialization decreased the TE of Kansas cow-calf farms, whereas Qushim et al. (2016) found that specialization increased the TE of U.S. meat goat farms. Offfarm is the percentage of annual net household income from off-farm sources, included using five levels in $20 \%$ intervals. Producers holding off-farm employment likely devote less attention to their farming operations, potentially resulting in lower output. Alternatively, off-farm income can be invested into the farm (Qushim et al., 2016).

The single-step maximum likelihood method (Battese and Coelli, 1995) was used to estimate equation (4) as an error components model. Specifically, the parameters of the stochastic IDF and the technical inefficiency models are estimated jointly using SPF techniques. There are biased estimation concerns associated with two-step methods (Schmidt, 2011). Accordingly, with least squares regression, if exogenous variables $W_{i}$ are omitted in the first step of a two-step estimation in which $W_{i}$ affects $Q_{i}$ and $X_{i}$ and $W_{i}$ are correlated, then $\beta$ will be biased. The first step results using two-step methods are biased if $X_{i}$ and $W_{i}$ are correlated and Monte Carlo (MC) simulations show that the bias can be severe (Schmidt, 2011).

\section{Results}

As previously discussed, data for this study were from both a first survey questionnaire including farm and farmer characteristics and a follow-up questionnaire for costs and returns. Therefore, our costs and returns data are a subsample of the first survey data. For that reason, there was concern as to whether there were differences between the first survey and the follow-up survey sample means. To compare the means of several variables in the first survey and those in the follow-up survey, we conducted $t$-tests to determine whether there were statistically significant differences in means of the following variables between the surveys: number of GFB cattle, total acres of GFB cattle, total farm acres, and years farming (Table 2), together providing information on whether farm size or farmer experience differed by survey. Results of the $t$-tests fail to 
Table 2. The $t$-Test Results for the First and Follow-up Survey Variable Means

\begin{tabular}{lll}
\hline \hline Variables & $t$-Test Value & $P$ Value \\
\hline Number of grass-fed beef cattle & -0.77 & 0.44 \\
Total acres of grass-fed beef cattle & -0.51 & 0.61 \\
Total farm acres & -0.64 & 0.52 \\
Total grass-fed beef production acres & -0.42 & 0.67 \\
Years farming & -0.02 & 0.98 \\
\hline \hline
\end{tabular}

reject the null hypothesis, concluding that there is not sufficient evidence to suggest the first survey and the follow-up survey sample means differ at $P \leq 0.10$ levels, suggesting that they came from similar GFB farms.

\subsection{Comparing Costs and Returns of U.S. GFB Farms by Operation Size}

To initially examine GFB production economics, the sample was divided into two operation sizes, small farms with $<15$ GFB slaughter-weight animals produced in 2012 and large farms with $\geq 15$ GFB slaughter-weight animals produced. There were 47 and 38 observations for small and large farms, respectively. Note that there is a difference between the total number of GFB animals in inventory and produced GFB slaughter-weight animals. GFB producers may not keep all animals to slaughter weight, and more than 1 year may be required to raise a GFB animal to slaughter weight. A comparison of U.S. GFB enterprise expenses (in dollar value) per slaughter-weight animal is shown in Table 3. GFB enterprise variable, fixed, and total specified expenses per slaughter-weight animal for large farms were lower than for small farms. GFB enterprise returns above total specified expenses per slaughter-weight animal for large farms were higher than for small farms but were negative. This underscores the value of estimating a multioutput stochastic IDF for these farms to obtain a better estimate of the impact of farm size on productivity.

A comparison of U.S. GFB enterprise expenses per production acre exclusively devoted to the GFB operation (small and large farms) is also shown in Table 3. Small farms were defined as those with $<100$ acres exclusively devoted to the GFB enterprise. Large farms had $\geq 100$ acres exclusively devoted to the GFB enterprise. Results show that GFB enterprise total, variable, and fixed expenses per acre for large farms were lower than for small farms. GFB enterprise return over variable expenses per acre for large farms was higher than for small farms. GFB enterprise return above total specified expenses per acre for large farms was higher than for small farms; however, this does not suggest that all large farm returns covered total expenses. Note, however, that 2012 was a year of severe drought in much of the United States (MacLachlan et al., 2018), so these conditions would have affected net returns for some producers. Small GFB farms, on average, used 3.3 acres per GFB animal compared with large farms with 
Table 3. U.S. Grass-Fed Beef (GFB) Enterprise Returns and Costs Comparison by SlaughterWeight Animals

\begin{tabular}{|c|c|c|}
\hline Return and Costs & Small Farms $(<15)$ & Large Farms $(\geq 15)$ \\
\hline & \multicolumn{2}{|c|}{ Dollars per GFB Slaughter-Weight Animal ${ }^{\mathrm{a}}$} \\
\hline Total revenue & $4,038.95$ & $1,740.19$ \\
\hline Total variable cost & $7,225.34^{\mathrm{B}}$ & $1,691.29^{\mathrm{A}}$ \\
\hline Return over variable cost & $-3,186.39$ & 48.91 \\
\hline Total fixed cost & $4,602.33^{\mathrm{A}}$ & $765.37^{\mathrm{B}}$ \\
\hline Total specified cost & $11,827.67^{\mathrm{B}}$ & $2,456.65^{\mathrm{A}}$ \\
\hline \multirow[t]{3}{*}{ Return over total cost } & $-7,788.73^{\mathrm{B}}$ & $-716.46^{\mathrm{A}}$ \\
\hline & Small Farms $(<100)$ & Large Farms $(\geq 100)$ \\
\hline & \multicolumn{2}{|c|}{ Dollars per GFB Land Acres ${ }^{b}$} \\
\hline Total revenue & 641.72 & 348.07 \\
\hline Total variable cost & $1,062.26^{\mathrm{B}}$ & $238.57^{\mathrm{A}}$ \\
\hline Return over variable cost & $-420.54^{\mathrm{B}}$ & $109.50^{\mathrm{A}}$ \\
\hline Total fixed cost & $444.76^{\mathrm{B}}$ & $114.47^{\mathrm{A}}$ \\
\hline Total specified cost & $1,507.02^{\mathrm{B}}$ & $353.04^{\mathrm{A}}$ \\
\hline Return over total cost & $-865.30^{\mathrm{B}}$ & $-4.97^{\mathrm{A}}$ \\
\hline
\end{tabular}

${ }^{\mathrm{a}}$ Letters $(\mathrm{A}, \mathrm{B})$ indicate significant differences $(P<0.10)$ in means across columns: $\mathrm{A}=$ small farms with $<15$ GFB animals that were raised to slaughter weight on the farm in 2012; B = large farms with $\geq 15$ GFB animals that were raised to slaughter weight on the farm in 2012.

${ }^{\mathrm{b}}$ Letters $(\mathrm{A}, \mathrm{B})$ indicate significant differences $(P<0.10)$ in means across columns: $\mathrm{A}=$ small farms with $<100$ acres that were exclusively devoted to the GFB operation in 2012 ; B = large farms with $\geq 100$ acres that were exclusively devoted to the GFB operation in 2012.

Note: The year 2012 was a year of severe drought in much of the United States, which would likely have affected costs and returns for GFB for some producers.

8.4 acres per GFB animal. Thus, although returns and expenses per acre values provide some insights, intensity of land use differed, complicating the simple comparison by farm size and providing further support for the quality adjustment to land as used in our IDF analyses.

\subsection{Estimating the Stochastic Input Distance Function}

The likelihood ratio test, $\mathcal{L} \mathcal{R}=\left(-2 \ln \left[\frac{\mathcal{L}\left(\mathrm{H}_{0}\right)}{\mathcal{L}\left(\mathrm{H}_{\mathrm{A}}\right)}\right]\right)$, was used to test the restrictions on the parameters of the stochastic IDF model, where $\ln \left[\mathcal{L}\left(\mathrm{H}_{0}\right)\right]$ and $\ln \left[\mathcal{L}\left(\mathrm{H}_{\mathrm{A}}\right)\right]$ are values of the likelihood function under null and alternative hypotheses, respectively. The likelihood ratio test has a chi-square $\left(\chi^{2}\right)$ distribution with the degrees of freedom given by the number of restrictions imposed in the translog model. Results of the test statistics for both U.S. GFB whole-farm and enterprise analyses are presented in Table 4.

First, we tested whether the explanatory variables in the inefficiency model significantly explained the technical inefficiency effects. Test results show that these effects are statistically explained by the variables in the inefficiency 
Table 4. The Likelihood Ratio (LR) Test Results for the U.S. Grass-Fed Beef Production Model

\begin{tabular}{|c|c|c|c|c|c|}
\hline $\mathrm{H}_{0}$ Restrictions & $\operatorname{Ln}\left[L\left(\mathrm{H}_{0}\right)\right]$ & $\operatorname{Ln}\left[L\left(\mathrm{H}_{\mathrm{A}}\right)\right]$ & LR & Critical $\chi^{2}$ & Restrictions \\
\hline \multicolumn{6}{|l|}{ Whole farm } \\
\hline \multicolumn{6}{|l|}{ No inefficiency } \\
\hline$\left(\tau_{0}=\tau_{1}=\cdots=\tau_{5}\right)$ & -49.95 & -39.06 & 21.78 & 16.92 & 6 \\
\hline $\begin{array}{l}\text { C- } \mathrm{D}^{\mathrm{a}} \text { production function }\left(\alpha_{3}=\cdots=\alpha_{5}=\right. \\
\left.\quad \beta_{3}=\cdots=\beta_{5}=\theta_{1}=\theta_{2}=\cdots=\theta_{4}\right)\end{array}$ & -59.40 & -39.06 & 40.68 & 28.87 & 10 \\
\hline \multicolumn{6}{|l|}{ Enterprise } \\
\hline \multicolumn{6}{|l|}{ No inefficiency } \\
\hline$\left(\tau_{0}=\tau_{1}=\cdots=\tau_{5}\right)$ & -71.89 & -52.65 & 38.48 & 16.92 & 6 \\
\hline $\begin{array}{l}\text { C-D } \mathrm{D}^{\mathrm{a}} \text { production function }\left(\alpha_{3}=\cdots=\alpha_{5}=\right. \\
\left.\beta_{3}=\cdots=\beta_{5}=\theta_{1}=\theta_{2}=\cdots=\theta_{4}\right)\end{array}$ & -83.58 & -52.65 & 61.86 & 28.87 & 10 \\
\hline
\end{tabular}

${ }^{\mathrm{a}} \mathrm{C}-\mathrm{D}$ is Cobb-Douglas production function.

Note: The test results at $5 \%$ level of significance.

models (Table 4). We also tested whether the translog functional form better described the underlying production technology of U.S. GFB farms relative to the alternative Cobb-Douglas functional form. Results show that the translog models are the more appropriate functional forms for the models.

The maximum likelihood parameter estimates ${ }^{5}$ for the stochastic IDF wholefarm and enterprise analyses are presented in Table 5. According to the estimated parameters, the stochastic IDF is found at the approximation point to be nondecreasing in inputs and nonincreasing in outputs. Moreover, the Hessian matrix of the first- and second-order partial derivatives with respect to inputs is found to be negative definite, and the corresponding Hessian matrix with respect to outputs to be positive definite. These indicate, respectively, the concavity and convexity of the underlying IDF with respect to inputs and outputs. The coefficient estimates for the output variable parameters in both analyses are significant and have expected signs. The statistically significant Cropl, Gfed, $G f b a h$, and Gfbm outputs suggest that increases in these outputs increase the productive contributions on both whole-farm and enterprise bases. In both the whole-farm and enterprise analyses, the second-order condition of cross effects of output, $\varepsilon_{X, Q_{k} Q_{l}}>0$, are positive and significant suggesting complimentary effects

$5 \mathrm{MC}$ simulation models were used to investigate finite-sample properties of the estimators given that the sample size in this study is not large. There may be concern that a small sample results in a lack of statistical representation of the population, resulting in inconsistency of estimates. Estimation results of the MC simulation showed there was no significant bias, and the asymptotic distribution approximated the finite-sample distribution well for the data generation process with 250, 500, and 1,000 replications. The mean of the point estimates was very close to the true value, the standard deviation of the point estimates was close to the mean of the standard errors, and the rejection rates were very close to the size of 0.05 . 
Table 5. The Input Distance Function (IDF) Estimates for U.S. Grass-Fed Beef Whole Farm and Enterprise

\begin{tabular}{|c|c|c|c|c|c|}
\hline Variables & Coefficient & $t$-Test & Variables & Coefficient & $t$-Test \\
\hline Whole Farm & & & Enterprise & & \\
\hline Constant & $-8.49^{* * *}$ & -3.51 & Constant & $-7.47^{* * *}$ & -5.34 \\
\hline$Q_{\text {Cropl }}^{d}$ & $3.61^{* * *}$ & 2.68 & $Q_{G F B a h}^{d}$ & 0.37 & 0.31 \\
\hline $\ln X_{\text {Varw }}^{*}$ & $0.57^{* * *}$ & 2.85 & $\ln X_{\text {Vare }}^{*}$ & $0.61^{* * *}$ & 3.64 \\
\hline $\ln X_{F i x w}^{*}$ & $0.43^{* *}$ & 2.03 & $\ln X_{\text {Fixe }}^{*}$ & $0.39^{* *}$ & 2.28 \\
\hline $\ln X_{\text {Varwsq }}^{*}$ & $0.26^{* * *}$ & 2.70 & $\ln X_{\text {Varesq }}^{*}$ & $0.19^{*}$ & 1.68 \\
\hline $\ln X_{\text {Fixwsq }}^{*}$ & 0.12 & 1.05 & $\ln X_{\text {Fixesq }}^{*}$ & 0.20 & 1.37 \\
\hline $\ln X_{\text {Varw }}^{*} \ln X_{\text {Fixw }}^{*}$ & $-0.37^{* *}$ & -2.00 & $\ln X_{\text {Vare }}^{*} \ln X_{\text {Fixe }}^{*}$ & $-0.40^{* *}$ & -2.09 \\
\hline $\ln Q_{\text {Cropl }}$ & $-0.36^{* *}$ & -2.48 & $\ln Q_{G F B a h}$ & $-0.37^{* * *}$ & -3.11 \\
\hline $\ln Q_{G f e d}$ & $-0.61^{* * *}$ & -3.11 & $\ln Q_{G F B m}$ & $-0.46^{* * *}$ & -4.43 \\
\hline $\ln Q_{\text {Croplsq }}$ & $-0.14^{* * *}$ & -3.70 & $\ln Q_{G F B a h s q}$ & -0.09 & -1.63 \\
\hline $\ln Q_{G f e d s q}$ & -0.08 & -0.37 & $\ln Q_{G F B m s q}$ & $-0.06^{* * *}$ & -4.68 \\
\hline $\ln Q_{\text {Cropl }} \ln Q_{G \text { fed }}$ & $0.08^{* * *}$ & 4.74 & $\ln Q_{G F B a b} \ln Q_{G F B m}$ & $0.05^{* * *}$ & 4.50 \\
\hline $\ln Q_{\text {Cropl }} \ln X_{\text {Varw }}^{*}$ & $-0.13^{* *}$ & -2.26 & $\ln Q_{G F B a b} \ln X_{\text {Vare }}^{*}$ & $-0.06^{* *}$ & -2.59 \\
\hline $\ln Q_{\text {Cropl }} \ln X_{\text {Fixw }}^{*}$ & -0.06 & -0.62 & $\ln Q_{G F B a b} \ln X_{F i x e}^{*}$ & $-0.05^{*}$ & -1.76 \\
\hline $\ln Q_{G f e d} \ln X_{\text {Varw }}^{*}$ & 0.03 & 2.02 & $\ln Q_{G F B m} \ln X_{\text {Vare }}^{*}$ & 0.02 & 1.00 \\
\hline $\ln Q_{G f e d} \ln X_{F i x w}^{*}$ & 0.08 & 1.02 & $\ln Q_{G F B m} \ln X_{\text {Fixe }}^{*}$ & 0.03 & 0.31 \\
\hline Neast & 0.02 & 0.15 & Neast & -0.14 & -0.73 \\
\hline Mwest & $-0.32^{* * *}$ & -4.30 & Mwest & $-0.79^{* * *}$ & -3.71 \\
\hline West & $-0.57^{* *}$ & -2.13 & West & $-0.39^{* *}$ & -2.34 \\
\hline Inefficiency & Model & & Inefficiency & Model & \\
\hline Constant & -6.25 & -0.87 & Constant & -1.92 & -0.86 \\
\hline College & $-1.46^{*}$ & -1.67 & College & $-0.92^{*}$ & -1.81 \\
\hline $\operatorname{Exp}$ & $-0.38^{*}$ & -1.87 & $\operatorname{Exp}$ & $-0.25^{* *}$ & -1.99 \\
\hline Farmsize & $-0.94^{* * *}$ & -2.84 & Farmsize & $-0.67^{* *}$ & -2.07 \\
\hline Gfbinc & $-2.22^{* *}$ & -2.03 & Gfbinc & $-0.46^{* * *}$ & -3.12 \\
\hline Offfarm & $-0.69^{* * *}$ & -3.32 & Offfarm & $-0.72^{* * *}$ & -2.70 \\
\hline sigma_v & 0.36 & 0.04 & & 0.38 & 0.10 \\
\hline
\end{tabular}

Notes: Asterisks (*, $\left.{ }^{* *},{ }^{* * *}\right)$ indicate $10 \%$ level of significance, $5 \%$ level of significance, and $1 \%$ level of significance, respectively. The standard errors for the IDF estimates are estimated using robust standard errors or the Huber-White estimator.

between the outputs. The second-order condition of cross effects of the inputs, $\varepsilon_{X, X_{m} X_{l}}<0$, indicate complementary effects between the inputs.

The estimates for inefficiency model parameters for both whole-farm and enterprise models are also presented in Table 5. College education, experience, farm size, farm specialization or percentage of annual net farm income from the GFB operation, and percentage of annual net household income from off-farm sources were efficiency drivers in both models. As expected, GFB producers with college degrees were more technically efficient than producers without college degrees. Greater experience with raising GFB led to more technically efficient GFB farms. Larger farms were more technically efficient than smaller farms. 
Table 6. Technical Efficiency (TE) Distributions

\begin{tabular}{|c|c|c|c|c|c|c|}
\hline Range of TE & Frequency & $\begin{array}{l}\% \text { of Farms in } \\
\text { TE Interval }\end{array}$ & Frequency & $\begin{array}{l}\% \text { of Farms in } \\
\text { TE Interval }\end{array}$ & Mean & $\begin{array}{l}\text { Standard } \\
\text { Deviation }\end{array}$ \\
\hline & \multicolumn{2}{|c|}{ Whole Farm } & \multicolumn{2}{|c|}{ Enterprise } & & \\
\hline $\mathrm{TE} \leq 0.10$ & 2 & 2.35 & 1 & 1.18 & & \\
\hline $0.10<\mathrm{TE} \leq 0.20$ & 3 & 3.53 & 1 & 1.18 & & \\
\hline $0.20<\mathrm{TE} \leq 0.30$ & - & - & 1 & 1.18 & & \\
\hline $0.30<\mathrm{TE} \leq 0.40$ & 4 & 4.71 & 4 & 4.71 & & \\
\hline $0.40<\mathrm{TE} \leq 0.50$ & 3 & 3.53 & 2 & 2.35 & & \\
\hline $0.50<\mathrm{TE} \leq 0.60$ & 1 & 1.18 & 6 & 7.06 & & \\
\hline $0.60<\mathrm{TE} \leq 0.70$ & 1 & 1.18 & 8 & 9.41 & & \\
\hline $0.70<\mathrm{TE} \leq 0.80$ & 4 & 4.71 & 21 & 24.71 & & \\
\hline $0.80<\mathrm{TE} \leq 0.90$ & 8 & 12.94 & 27 & 31.76 & & \\
\hline $0.90<\mathrm{TE} \leq 1.00$ & 56 & 65.88 & 14 & 16.47 & & \\
\hline Total & 85 & 100.00 & 85 & 100.00 & & \\
\hline TE (whole farm) & & & & & 0.84 & 0.23 \\
\hline TE (enterprise) & & & & & 0.79 & 0.17 \\
\hline
\end{tabular}

Statistical significance of GFB production specialization provides no initial evidence of economies of scope in GFB whole-farm production; farms that were more specialized were more efficient than farms that were more diversified. In both whole-farm and enterprise models, GFB producers having greater percentages of income from off-farm sources were more technically efficient than producers with lower percentages of income from off-farm sources. This suggests that having off-farm employment causes producers to more efficiently utilize their inputs (including labor) in producing GFB.

The distributions of the estimated input-oriented TE scores for both wholefarm and enterprise models are presented in Table 6 . We find average TE scores of 0.84 and 0.79 , respectively, for GFB farms on whole-farm and enterprise bases. This implies that the average U.S. GFB farm could reduce inputs by $16 \%$ (wholefarm basis) and $21 \%$ (GFB enterprise basis) to produce the same output as an efficient operation on the production frontier. The table also shows that more than $78 \%$ and $48 \%$ of the producers achieved TE levels of $80 \%$ or higher using whole-farm and enterprise measures, respectively. Featherstone, Langemeier, and Ismet (1997) and Rakipova, Gillespie, and Franke (2003) found average TEs of 0.78 and 0.92 for Kansas and Louisiana beef cattle producers, respectively. Relatively low TE levels would be expected for the GFB industry given the relative newness of GFB production to many U.S. farms and limited research to provide recommendations for productive GFB production. To compare the distribution of TE differences between large and small farms, we conducted a nonparametric Kruskal-Wallis test. We defined large farms as operation sizes $\geq 50$ GFB animals in inventory, and otherwise small farms. The test results indicate the statistical significance of the Kruskal-Wallis test at $P \leq 0.05$. 
Table 7. Marginal Productive Contributions (MPCs) for Inputs and Outputs, Returns to Scale, Scope Economies, and Scale Efficiency

\begin{tabular}{|c|c|c|c|c|c|}
\hline MPCs & Coefficient & $t$-Test & MPCs & Coefficient & $t$-Test \\
\hline & \multicolumn{2}{|c|}{ Whole Farm } & & \multicolumn{2}{|c|}{ Enterprise } \\
\hline $\ln X_{\text {Landw }}$ & $-0.49^{* * *}$ & -2.70 & $\ln X_{\text {Lande }}$ & $-0.57^{* * *}$ & -4.14 \\
\hline $\ln X_{\text {Varw }}^{*}$ & $-0.26^{* * *}$ & -2.63 & $\ln X_{\text {Vare }}^{*}$ & $-0.37^{* *}$ & -2.09 \\
\hline $\ln X_{\text {Fixw }}^{*}$ & $-0.24^{* *}$ & -2.28 & $\ln X_{\text {Fixe }}^{*}$ & $-0.22^{* * *}$ & -2.78 \\
\hline $\ln Q_{\text {Cropl }}$ & $0.34^{*}$ & 1.89 & $\ln Q_{G f b a b}$ & $0.27^{*}$ & 1.80 \\
\hline $\ln Q_{G f e d}$ & $0.54^{* *}$ & 2.21 & $\ln Q_{G f b m}$ & $0.59^{* * *}$ & 4.72 \\
\hline Measurements & \multicolumn{2}{|c|}{ Whole Farm } & & \multicolumn{2}{|c|}{ Enterprise } \\
\hline Returns to scale & $0.88^{* *}$ & 4.74 & & $0.86^{* * *}$ & 4.11 \\
\hline Scale efficiency & $1.00^{* * *}$ & 105.72 & & $1.00^{* * *}$ & 130.69 \\
\hline Scope economies & - & - & & $0.11^{* * *}$ & 4.50 \\
\hline
\end{tabular}

Notes: Asterisks $\left(*,{ }^{* *},{ }^{* * *}\right)$ indicate $10 \%$ level of significance, $5 \%$ level of significance, and $1 \%$ level of significance, respectively.

Estimated parameters of MPCs for both whole-farm and enterprise models have theoretically correct signs, negative for inputs and positive for outputs (Table 7). MPCs for output indicate an increase in overall input use when output expands. For inputs, MPCs indicate the shadow values of inputs relative to land. All of the MPC measures in both whole-farm and enterprise analyses are statistically significant. The largest MPC in absolute value for inputs is land expense, followed by total variable expenses and total fixed expenses. The MPC for GFB production output in the whole-farm model has the largest output share-about $54 \%$ on average. The MPC for GFB meat production output in the enterprise model has the largest output share-nearly $59 \%$ on average.

GFB production overall economic performance indicators for both wholefarm and enterprise analyses are presented in Table 7. The estimated RTS parameters for U.S. GFB whole-farm and enterprise analyses show that a $1 \%$ increase in all outputs increased overall input use by $0.88 \%$ and $0.86 \%$, respectively. These results imply an increasing RTS economy for U.S. GFB production. A measure of scope economies was estimated from the IDF by taking the second cross partial output derivatives, and it was statistically significant only for the enterprise analysis. The scope economies parameter suggests that the joint production of both GFB animal and GFB meat outputs decreased average total cost by $11 \%$ relative to the separate production of these two outputs on U.S. GFB farms.

As an economic performance measure, SEF represents the improvement in average productivity of U.S. GFB farms through a change in the scale of GFB production. The SEF measures estimated from the IDF are presented in Table 7. We used the stochastic IDF parameter estimates to determine SEF for GFB 
production using equation (8). Different sizes of GFB farm operations as well as the median size of GFB farms were entered into the SEF equation (8) to achieve the SEF measure of 1 . The median size of the farms is 50 animals in our sample. Results of SEF measures from both whole-farm and enterprise analyses indicate that, on average, GFB farms are scale efficient if the farm's scale of production is greater than 100 animals in inventory. The SEF measure indicated that GFB farms are not scale efficient based on the median farm size, which is 50 animals.

\section{Summary and Conclusions}

Because the U.S. GFB industry has only recently experienced increased interest after many decades of little interest from U.S. producers and consumers, the relatively few producers who have become recently involved in the industry have had little access to information on the most efficient practices for GFB production. To reveal insights on productivity drivers in this growing segment of the beef industry, we estimated efficiency measurements including TE, scale and scope economies, and SEF for U.S. GFB production using costs and returns data. Given that our sample size is relatively small with approximately two farms per state, we suggest that results should be interpreted with caution. As such, these economic efficiency measures are conclusions of our survey sample analysis rather than the entire U.S. GFB industry. However, given that our survey sample is likely representative of the commercial U.S. GFB producers who advertised their products via the Internet (which are likely a sizable portion of the GFB producer population), our results hold some significant implications.

The effect of operation size on the efficiency and productivity of U.S. GFB enterprises is significant. A look at farm costs and returns generally showed lower costs per unit of input on both per slaughter animal produced and per acre bases for large farms. The large farms had positive cash returns (returns over variable cost) even during a drought year. The 2012 drought affected feed availability, animal mortality rates, production costs, and income for livestock producers (MacLachlan et al., 2018). However, results of simple GFB enterprise costs and returns analyses by farm size present some problems, as there are significant differences in output mix within the GFB enterprise, with some producers concentrating more heavily on animal sales (generally larger farms) and others concentrating more heavily on meat sales (generally smaller farms). Furthermore, land quality varies significantly, so simple per acre of land estimates must be interpreted with caution. These issues provide some justification for the use of multiple-input, multiple-output distance functions where output and input mixes are considered and land quality adjustments are made. Using the IDF analysis, larger GFB operations were determined to be more technically efficient than smaller operations. The IDF estimates indicate that there are significant economies of size in U.S. GFB production. Increasing RTS suggests that by expanding their operations, producers can use less input per unit produced. 
Results suggest that U.S. GFB farms can be scale efficient if they have greater than approximately 100 GFB animals in inventory. The average GFB farm in our sample had 100 animals in inventory, suggesting there is significant potential for increased SEF in this industry. It is noted, however, that a farm with $100 \mathrm{GFB}$ animals is relatively large scale by U.S. farm standards. From our survey, the average 100-animal operation farmed 667 acres of land, as compared with the average U.S. farm of 433 acres (USDA, National Agricultural Statistics Service, 2012).

Scope economies were found through vertically integrating within the GFB supply chain. Producers who sold GFB meat and GFB animals reduced their longrun average costs of production. On a whole-farm basis, however (considering non-GFB enterprises), scope economies were not found. In addition to the scope economies estimate being nonsignificant for the whole-farm model, having higher percentages of farm returns from GFB (greater specialization in GFB) increased farm efficiency. Thus, we find no evidence to suggest that economies of scope are present in producing GFB along with other agricultural commodities.

Another way to diversify farm household income is via off-farm income. Greater off-farm income increased TE, perhaps because of the investment of offfarm income on GFB operations. Income from off-farm sources provides capital for producers to adopt new technologies and perhaps purchase more productive inputs for their operations, which in turn can lead to increased TE. Furthermore, because of time constraints, the operator labor input must be utilized more efficiently for an operator with off-farm employment to produce the same output as the full-time producer. Note that mixed results have been found in previous studies examining the impact of off-farm income on TE.

The inefficiency model estimates also reveal some additional insights. Not surprisingly, both more highly educated producers and those with more GFB farming experience operated more technically efficient farms. Considering (1) the wide range of options available to GFB producers in terms of production system (continuous or rotational grazing, etc.), breed types, and forage types; (2) the different production conditions (climate, weather, soil, etc.) under which GFB is produced; and (3) the limited research available to provide insights into the best GFB production practices, production experience would be expected to be quite important for increasing productivity in this industry.

If current trends of increased supply and demand for GFB continue for the foreseeable future, we expect more questions from current and potential GFB producers on recommended farm structure and optimal production practices. Given the many different forage species and production conditions across the United States, more targeted regional analysis would be helpful. In areas where there is particularly heightened interest in GFB, this introduces the need for research and extension efforts in this area. Although the current study provides insight into some general GFB farm structural issues such as farm size, diversification, and so forth, more specific production system questions will need 
to be addressed through field trials and economic analyses along the lines of those conducted by Bhandari et al. (2015) for GFB. Coupled with the results of studies such as the present one, such studies can provide producers with guidance on how to structure their operations in a way such that profit potential is strengthened.

\section{References}

Balk, B.M. "Scale Efficiency and Productivity Change." Journal of Productivity Analysis 15,3(2001):159-83.

Ball, V.E., W.A. Lindamood, R. Nehring, and C.S.J. Mesonada. "Capital as a Factor of Production in OESD Agriculture: Measurement and Data." Applied Economics 40,10(2008):1253-77.

Battese, G.E. "A Note on the Estimation of Cobb-Douglas Production Functions When Some Explanatory Variables Have Zero Values.” Journal of Agricultural Economics 48,13(1997):250-52.

Battese, G.E., and T.J. Coelli. "A Model for Technical Inefficiency Effects in a Stochastic Frontier Production Function for Panel Data.” Empirical Economics 20,2(1995):32532.

Bhandari, B.D., J. Gillespie, G. Scaglia, J. Wang, and M. Salassi. “Analysis of Pasture Systems to Maximize the Profitability and Sustainability of Grass-Fed Beef Production.” Journal of Agricultural and Applied Economics 47,2(2015):193-212.

Bhatt, M.S., and S.A. Bhat. "Technical Efficiency and Farm Size Productivity-Micro Level Evidence from Jammu \& Kashmir." International Journal of Food and Agricultural Economics 2,4(2014):27-49.

Coelli, T., G. Hajargasht, and C.A. Knox Lovell. "Econometric Estimation of an Input Distance Function in a System of Equations.” Working Paper Series No. WP01/2008, Brisbane, Queensland, Australia: Center for Efficiency and Productivity Analysis, School of Economics, University of Queensland.

Coelli, T.J., and S. Perelman. "A Comparison of Parametric and Nonparametric Distance Functions: With Application to European Railways.” European Journal of Operations Research 117,2(1999):326-39.

Coelli, T.J., D.S. Prasado Rao, C.J. O’Donnell, and G.E. Battese. An Introduction to Efficiency and Productivity Analysis. 2nd ed. New York: Springer, 2005.

Cox, R.B., C.R. Kerth, J.G. Gentry, J.W. Prevatt, K.W. Braden, and W.R. Jones. "Determining Acceptance of Domestic Forage- or Grain-Finished Beef by Consumers from Three Southeastern U.S. States.” Journal of Food Science 71,7(2006):2762-71.

Dillman, D.A., J.D. Smith, and L.M. Christian. Internet, Mail, and Mixed-Mode Surveys: The Tailored Design Method. 3rd ed. Hoboken, NJ: John Wiley and Sons, 2009.

Färe, R., and D. Primont. Multi-output Production and Duality: Theory and Applications. Boston: Kluwer Academic, 1995.

Featherstone, A.M., M.R. Langemeier, and M. Ismet. "A Nonparametric Analysis of Efficiency for a Sample of Kansas Beef Cow Farms." Journal of Agricultural and Applied Economics 29,1(1997):175-84.

Gwin, L. "Scaling-up Sustainable Livestock Production: Innovation and Challenges for Grassfed Beef in the U.S.” Journal of Sustainable Agriculture 33,2(2009):189-209. 
Iraizoz, B., I. Bardaji, and M. Rapun. "The Spanish Beef Sector in the 1990s: Impact of the BSE Crisis on Efficiency and Profitability." Applied Economics 37,4(2005): 473-84.

Jondrow, J., C.A. Knox Lovell, I.S. Materov, and P. Schmidt. “On the Estimation of Technical Inefficiency in the Stochastic Frontier Production Model." Journal of Econometrics 19,2-3(1982):223-38.

Kumbhakar, S.C., and C.A. Knox Lovell. Stochastic Frontier Analysis. Cambridge: Cambridge University Press, 2000.

MacLachlan, M., S. Ramos, A. Hungerford, and S. Edwards. Federal Natural Disaster Assistance Programs for Livestock Producers, 2008-16. Washington, DC: U.S. Department of Agriculture, Economic Research Service, Economic Information Bulletin No. 187, January 2018.

Mathews, K.H. Jr., and R.J. Johnson. Alternative Beef Production Systems: Issues and Implications. Washington, DC: U.S. Department of Agriculture, Economic Research Service, LDPM-218-01, 2013.

McCluskey, J. J., T. I. Wahl, Q. Li, and P. R. Wandschneider. “U.S. Grass-Fed Beef: Marketing Health Benefits." Journal of Food Distribution Research 36,3(2005):1-8.

Mills, B. "Carving a Grass-Finished Niche." Beef. March 1, 2003. Internet site: http:// beefmagazine.com/mag/beef_carving_grassfinished_niche (Accessed June 7, 2016).

Morrison Paul, C.J., and R. Nehring. "Product Diversification, Production Systems, and Economic Performance in U.S. Agricultural Production." Journal of Econometrics 126,2(2005):525-48.

Morrison Paul, C., R. Nehring, D. Banker, and A. Somwaru. "Scale Economies and Efficiency in U.S. Agriculture: Are Traditional Farms History?” Journal of Productivity Analysis 22,3(2004):185-205.

Pelletier, N., R. Pirog, and R. Rasmussen. "Comparative Life Cycle Environmental Impacts of Three Beef Production Strategies in the Upper Midwestern United States.” Agricultural Systems 103,6(2010):380-89.

Qushim, B., J. Gillespie, K. Paudel, and K. Mcmillin. "Technical and Scale Efficiencies of Meat Goat Farms in the USA.” Applied Economics 48,7(2016):608-20.

Rakipova, A.N., J.M. Gillespie, and D.E. Franke. "Determinants of Technical Efficiency in Louisiana Beef Cattle Production." Journal of the American Society of Farm Management and Rural Appraisers 2003(2003):99-107.

Ray, S.C. "Measuring Scale Efficiency from a Translog Production Function.” Journal of Productivity Analysis 11,2(1998):183-94.

- "Measure Scale Efficiency from the Translog Multi-Input, Multi-Output Distance Function.” Economic Working Paper No. 200325, Storrs: Department of Economics, University of Connecticut, 2003.

Rubin, D.B. Multiple Imputation for Nonresponse in Surveys. New York: John Wiley and Sons, 1987.

Samarajeewa, S., G. Hailu, S.R. Jeffrey, and M. Bredahl. "Analysis of Production Efficiency of Beef Cow-Calf Farms in Alberta.” Applied Economics 44,3(2012):313-22.

Schafer, J.L. Analysis of Incomplete Multivariate Data. Boca Raton, FL: CRC Press, 1997.

Schmidt, P. "One-Step and Two-Step Estimation in SFA Models." Journal of Productivity Analysis 36,2(2011):201-3.

Umberger, W.J., P.C. Boxall, and R.C. Lacy. "Role of Credence and Health Information in Determining U.S. Consumers' Willingness-to-Pay for Grass-Finished Beef.” Australian Journal of Agricultural and Resource Economics 53,4(2009):603-23. 
Umberger, W.J., D.M. Feuz, C.R. Calkins, and K. Killinger. "U.S. Consumer Reference and Willingness-to-Pay for Domestic Corn-Fed Beef Versus International GrassFed Beef Measured through an Experimental Auction.” Agribusiness 18,4(2002): 491-504.

U.S. Department of Agriculture, Agricultural Marketing Service. National Monthly Grass Fed Beef Report. 2017. Internet site: https://www.ams.usda.gov/mnreports/lsmngfbeef.pdf (Accessed November 3, 2017).

U.S. Department Agriculture, Economic Research Service (USDA-ERS). "Beef Trade." 2015. Internet site: http://www.ers.usda.gov/topics/animal-products/cattle-beef/trade. aspx (Accessed July 1, 2016).

. "Cattle and Beef." 2012. Internet site: http://www.ers.usda.gov/topics/animalproducts/cattle-beef.aspx (Accessed July 1, 2016).

U.S. Department Agriculture, National Agricultural Statistics Service. "2012 Census of Agriculture - United States Data." Internet site: https://www.nass.usda.gov/ Publications/Ag_Statistics/2014/chapter09.pdf (Accessed July 1, 2016).

Williams, A. "The Future of Grassfed: Laying out the Promise and Challenges." Graze. November 1, 2013. Internet site: http://www.grazeonline.com/grassfedpromisechallenge (Accessed July 1, 2016). 